\title{
Antacid Therapy and Disease Progression in Patients with Idiopathic Pulmonary Fibrosis Who Received Pirfenidone
}

\author{
Michael Kreuter ${ }^{\mathrm{a}, \mathrm{b}}$ Paolo Spagnolo ${ }^{c}$ Wim Wuyts $^{\mathrm{d}}$ Elisabetta Renzoni ${ }^{\mathrm{e}}$ \\ Dirk Koschel $^{f}$ Francesco Bonellag Toby M. Mahere Martin Kolb ${ }^{\text {h }}$ \\ Derek Weycker ${ }^{i}$ Klaus-Uwe Kirchgässler ${ }^{j} \quad$ Ulrich Costabel ${ }^{g}$
}

\begin{abstract}
${ }^{a}$ Center for Interstitial and Rare Lung Diseases, Pneumology and Respiratory Critical Care Medicine, Thoraxklinik, University of Heidelberg, and ${ }^{\mathrm{b}}$ Translational Lung Research Center, Heidelberg, and member of the German Center for Lung Research, Germany; ' Section of Respiratory Diseases, Department of Cardiac, Thoracic, and Vascular Sciences, University of Padua, Padua, Italy; ${ }^{d}$ Unit for Interstitial Lung Diseases, Department of Respiratory Medicine, University Hospitals, Leuven, Belgium; ${ }^{e}$ National Institute for Health Biomedical Research Unit, Royal Brompton Hospital and National Heart and Lung Institute Imperial College, London, UK; ${ }^{f}$ Department of Pulmonary Diseases, Fachkrankenhaus Coswig, Center for Pulmonary Diseases and Thoracic Surgery, Coswig, and 9Interstitial and Rare Lung Disease Unit, Ruhrlandklinik, University Hospital, University of Duisburg-Essen, Essen, Germany; ${ }^{\text {h}}$ Firestone Institute for Respiratory Health, Department of Medicine, Pathology \& Molecular Medicine, McMaster University, Hamilton, ON, Canada; 'Policy Analysis Inc., MINERVA Health Economics Network Ltd., Brookline, MA, USA;

jF. Hoffmann-La Roche Ltd., Basel, Switzerland
\end{abstract}

\section{Keywords}

Antacid therapy · Gastroesophageal reflux disease . Idiopathic pulmonary fibrosis . Pirfenidone.

Progression-free survival

\begin{abstract}
Background: Gastroesophageal reflux disease is a potential risk factor for idiopathic pulmonary fibrosis (IPF) progression; however, the impact of antacid therapy (AAT) is under debate. Objective: To evaluate the effect of AAT on IPF progression in pirfenidone-treated patients. Methods: This post hoc analysis included patients with IPF who received pirfenidone in 3 trials (CAPACITY [PIPF-004/PIPF-006] and ASCEND [PIPF-016]). Pulmonary function, exercise tolerance, survival, hospitalizations, and adverse events (AEs) over 52 weeks were analyzed by baseline AAT use. Disease progression was
\end{abstract}

\section{KARGER}

E-Mail karger@karger.com www.karger.com/res
This article is licensed under the Creative Commons AttributionNonCommercial-NoDerivatives 4.0 International License (CC BY NC-ND) (http://www.karger.com/Services/OpenAccessLicense). Usage and distribution for commercial purposes as well as any distribution of modified material requires written permission. defined as a decrease in forced vital capacity (FVC) of $\geq 10 \%$, a decrease in 6-min walking distance of $\geq 50 \mathrm{~m}$, or death over 1 year. Results: Of 623 patients, 44\% received AAT. No significant differences were found at 52 weeks (AAT versus nonAAT, respectively) in disease progression ( 24.9 vs. $30.6 \% ; p=$ 0.12 ), all-cause mortality rate ( 2.9 vs. $4.0 \% ; p=0.47$ ), IPF-related mortality rate ( $1.1 \mathrm{vs.} 2.0 \% ; p=0.37$ ), all-cause hospitalization rate ( 16.1 vs. $18.3 \% ; p=0.48)$, or mean change in percent FVC ( -2.7 vs. $-3.1 \% ; p=0.44)$. A relative, but not absolute, FVC decline of $\geq 10 \%$ favored AAT ( 15 vs. $22 \% ; p=0.03$ ). Severe gastrointestinal AEs (3.7 vs. $0.9 \% ; p=0.015)$ and severe pulmonary infections ( 3.7 vs. $1.1 \% ; p=0.035$ ) were more frequent with AAT. Conclusions: AAT and pirfenidone had outcomes comparable to those of pirfenidone alone in patients with IPF, underscoring the need for prospective trials to elucidate the role of AAT with or without antifibrotic drugs as a treatment for IPF.

(c) 2017 The Author(s) Published by S. Karger AG, Basel

Michael Kreuter, MD

Center for Interstitial and Rare Lung Diseases, Pneumology and Respiratory Critical Care Medicine, Thoraxklinik, University of Heidelberg

Röntgenstr. 1, DE-69126 Heidelberg (Germany)

E-Mail kreuter@uni-heidelberg.de 


\section{Introduction}

Idiopathic pulmonary fibrosis (IPF) is a debilitating, progressive, unpredictable, and ultimately fatal fibrosing lung disease characterized by a relentless decline in lung function, worsening dyspnea, and diminished exercise tolerance. The rate of IPF progression can vary from person to person, and the median survival time from diagnosis is $2-3$ years [1]. Pirfenidone and nintedanib have demonstrated significant slowing of disease progression in clinical trials compared with placebo and are approved for the treatment of IPF [2-4].

The clinical efficacy and safety of pirfenidone were demonstrated in 4 randomized controlled phase 3 trials [3-6]. Efficacy data from these trials, and a pooled analysis, confirmed a clinically meaningful benefit of pirfenidone compared with placebo in multiple measures of disease status, including 6-min walking distance (6MWD), forced vital capacity (FVC), and progression-free survival (PFS).

Comorbidities - such as cardiovascular disease, lung cancer, and gastroesophageal reflux disease (GERD) - significantly affect the symptoms and survival associated with IPF [7]. GERD is characterized by heartburn, dyspepsia, regurgitation, and chest pain [8]. The incidence of GERD is higher in patients with IPF $(8-87 \%)$ compared with the general population (10-38\%) [9-13]. This may be due to shared risk factors, including age and smoking [14]. GERD may also be induced by lung fibrosis, but the causal relationship is unclear [15-18]. The treatment of GERD includes lifestyle interventions, antacid therapy (AAT) with histamine $\mathrm{H}_{2}$ receptor antagonists $\left(\mathrm{H}_{2}\right.$ blockers $)$ or proton pump inhibitors (PPIs), and fundoplication [8]. PPIs (not $\mathrm{H}_{2}$ blockers) may have antifibrotic properties that act independently of gastric acid neutralization [19]. Current treatment guidelines give a conditional recommendation for AAT in patients with IPF, albeit with very low confidence in estimates of effect [20]. Although some studies have demonstrated that AAT is associated with longer survival time and slower disease progression, recent post hoc analyses do not support a protective effect of AAT on disease progression in patients with IPF [21, 22], which led to some discussion on the role of AAT in IPF [23-25]. The impact of AAT on disease progression in patients with IPF who receive pirfenidone is unknown.

The objective of this study was to compare the incidence of the composite endpoint of disease progression as well as other clinical outcomes - including mortality, change in FVC, change in 6MWD, and hospitalization rate - between patients with IPF randomized to pirfenidone in 3 large phase 3 trials stratified by AAT at baseline.

\section{Subjects and Methods}

Study Population

The study population included all patients with IPF randomized to $2,403 \mathrm{mg} /$ day pirfenidone in 3 trials (CAPACITY [PIPF004], NCT00287716; CAPACITY [PIPF-006], NCT00287729; and ASCEND [PIPF-016], NCT01366209); patients randomized to a lower dose were excluded. Patients were stratified into 2 subgroups on the basis of AAT use (i.e., yes versus no; either $\mathrm{H}_{2}$ blockers and/ or PPIs) at trial baseline. The eligibility criteria for the trials were previously described $[3,4]$. All trial participants provided written informed consent, and the ethics committee or institutional review board at each participating institution approved the protocol for each trial.

\section{Data Collection}

Data collected included patient demographic and clinical characteristics, pulmonary function (e.g., FVC and hemoglobin-corrected predicted diffusing capacity of the lung for carbon monoxide $\left[\mathrm{DL}_{\mathrm{CO}}\right]$ ), exercise tolerance (6MWD), dyspnea (University of California at San Diego Shortness of Breath Questionnaire [UCSD-SOBQ] score), medication use (e.g., $\mathrm{H}_{2}$ blockers and PPIs), indication for use, adverse events (AEs), hospitalization rate, and vital status. FVC, 6MWD, and UCSD-SOBQ score were measured at trial baseline and periodically during the trial; $\mathrm{DL}_{\mathrm{CO}}$ was assessed after baseline only in the CAPACITY trials. PFS was defined as the time to the first occurrence of a confirmed decrease in predicted $\mathrm{FVC}$ of $\geq 10 \%$, a confirmed decrease in $6 \mathrm{MWD}$ of $\geq 50$ $\mathrm{m}$, or death. The primary cause of any death and its relation to IPF were assessed in a blinded fashion by an independent mortality assessment committee in the ASCEND trial [3] and by the site investigators in the CAPACITY trials [4]. For this study, all safety events through 52 weeks were considered. Severe gastrointestinal (GI)related side effects and severe pulmonary infections were defined as grade 3 or 4 (grade 3 is severe and grade 4 is life-threatening).

Post hoc Analysis of Study Outcomes

The primary study outcome of disease progression was defined as a decrease in FVC of $\geq 10 \%$, a decrease in $6 \mathrm{MWD}$ of $\geq 50 \mathrm{~m}$, or death (whichever occurred first) over 1 year from baseline. Functional worsening (FVC decrease of $\geq 10 \%$ and/or $6 \mathrm{MWD}$ decrease of $\geq 50 \mathrm{~m}$ ) was considered only when observed on 2 consecutive occasions $\geq 6$ weeks apart. Secondary outcomes included all-cause and IPF-related mortality, decreases in FVC (absolute and relative decreases of $\geq 5$ and $\geq 10 \%$, respectively), all-cause and IPF-related hospitalization rates, and potentially important AEs (GI-related AEs, infections, and severe pulmonary infections). Outcomes were additionally analyzed based on patient FVC baseline of greater lung function loss (FVC $<70 \%$ ) and less lung function loss (FVC $\geq 70 \%$ ). A baseline FVC of $70 \%$ was chosen because it was the mean FVC of the patient population.

\section{Statistical Analyses}

The demographic and clinical characteristics of the study population were evaluated separately by trial, collectively and stratified by use of AAT at baseline. Unadjusted risks of binary study outcomes as well as changes from baseline in FVC and 6MWD among baseline users of AAT versus baseline nonusers were compared using an independent-sample $t$ test for continuous variables and $\chi^{2}$ test for categorical variables. AAT use was examined against binary study outcomes using a shared frailty model (an extension of the
416

Respiration 2017;93:415-423

DOI: $10.1159 / 000468546$
Kreuter et al. 
Table 1. Baseline demographics and clinical characteristics by antacid therapy use

\begin{tabular}{|c|c|c|c|}
\hline & $\begin{array}{l}\text { AAT } \\
(n=273)\end{array}$ & $\begin{array}{l}\text { No AAT } \\
(n=350)\end{array}$ & $p$ value \\
\hline \multicolumn{4}{|l|}{ Age, years } \\
\hline Mean \pm SD & $67.9 \pm 7.8$ & $66.7 \pm 7.3$ & 0.0499 \\
\hline Median (IQR) & $69(62-74)$ & $67(62-72)$ & - \\
\hline Male & $195(71.4 \%)$ & $268(76.6 \%)$ & 0.1449 \\
\hline \multicolumn{4}{|l|}{ Physiological (mean \pm SD) } \\
\hline FVC, \% predicted & $71.6 \pm 13.4$ & $71.6 \pm 13.1$ & 0.9909 \\
\hline $\mathrm{DL}_{\mathrm{CO}}, \%$ predicted & $45.7 \pm 10.0$ & $45.5 \pm 10.3$ & 0.7878 \\
\hline $6 \mathrm{MWD}$ & $396.8 \pm 90.2$ & $409.3 \pm 96.1$ & 0.1013 \\
\hline \multicolumn{4}{|l|}{ Dyspnea $($ mean $\pm \mathrm{SD})$} \\
\hline UCSD-SOBQ & $34.7 \pm 21.5$ & $33.8 \pm 21.3$ & 0.6299 \\
\hline \multicolumn{4}{|l|}{ Medical history } \\
\hline \multicolumn{4}{|l|}{ Comorbidities } \\
\hline CVD & $79(28.9 \%)$ & $90(25.7 \%)$ & 0.3693 \\
\hline CRF & $6(2.2 \%)$ & $6(1.7 \%)$ & 0.6631 \\
\hline COPD & $14(5.1 \%)$ & $8(2.3 \%)$ & 0.0565 \\
\hline Pulmonary embolism & $4(1.5 \%)$ & $5(1.4 \%)$ & 0.9697 \\
\hline Pulmonary hypertension & $7(2.6 \%)$ & $7(2.0 \%)$ & 0.6374 \\
\hline Atrial fibrillation & $14(5.1 \%)$ & $17(4.9 \%)$ & 0.8773 \\
\hline Sleep apnea & $45(16.5 \%)$ & $46(13.1 \%)$ & 0.2414 \\
\hline \multicolumn{4}{|l|}{ Gastrointestinal comorbidities } \\
\hline GERD & $236(86.4 \%)$ & $84(24.0 \%)$ & $<0.001$ \\
\hline Hiatal hernia & $35(12.8 \%)$ & $19(5.4 \%)$ & 0.0011 \\
\hline Barrett esophagus & $14(5.1 \%)$ & $2(0.6 \%)$ & $<0.001$ \\
\hline HP-positive gastritis & $1(0.4 \%)$ & $1(0.3 \%)$ & 0.8600 \\
\hline \multicolumn{4}{|l|}{ Cardiovascular risk factors } \\
\hline Hypertension & $142(52.0 \%)$ & $168(48.0 \%)$ & 0.3200 \\
\hline Smoker (current/former) & $180(65.9 \%)$ & $226(64.6 \%)$ & 0.7232 \\
\hline Diabetes & $63(23.1 \%)$ & $87(24.9 \%)$ & 0.6061 \\
\hline Hypercholesterolemia & $149(54.6 \%)$ & $161(46.0 \%)$ & 0.0336 \\
\hline Obesity (BMI >30) & $128(46.9 \%)$ & $156(44.6 \%)$ & 0.5649 \\
\hline PPI use only & $245(89.74 \%)$ & - & - \\
\hline $\mathrm{H}_{2}$ use only & $17(6.23 \%)$ & - & - \\
\hline $\mathrm{PPI}+\mathrm{H}_{2}$ use & $11(4.03 \%)$ & - & - \\
\hline
\end{tabular}

Values are presented as $n$ (\%) unless indicated otherwise. 6MWD, 6-min walking distance; AAT, antacid therapy; BMI, body mass index; COPD, chronic obstructive pulmonary disease; $\mathrm{CRF}$, chronic respiratory failure; $\mathrm{CVD}$, cardiovascular disease; $\mathrm{DL}_{\mathrm{CO}}$, hemoglobin-corrected predicted diffusing capacity of the lung for carbon monoxide; FVC, forced vital capacity; GERD, gastroesophageal reflux disease; $\mathrm{H}_{2}$, histamine $\mathrm{H}_{2}$ receptor antagonist; HP, Helicobacter pylori; IQR, interquartile range; PPI, proton pump inhibitor; SD, standard deviation; UCSD-SOBQ, University of California at San Diego Shortness of Breath Questionnaire.
Cox proportional hazards model that adjusts for intracluster [i.e., intratrial] correlation), without and with adjustment for age, sex, smoking status, lung function, and comorbidity profile. Survival curves were estimated based on the corresponding multivariate models and using the mean of covariates method; comparisons were based on the likelihood ratio test. Only observed data were used. Individuals were censored at the time of loss to follow-up, at the time of lung transplant, or at the end of the 1-year follow-up period, whichever occurred first. The presence of multicollinearity, hazards assumptions, and treating death as a competing risk (when appropriate) were evaluated using published methods [26, 27].

Antacid Therapy and Pirfenidone Use in

Idiopathic Pulmonary Fibrosis

\section{Results}

A total of 623 patients were included in the study, of whom 273 (43.8\%) received AAT (89.74\% PPIs, 6.23\% $\mathrm{H}_{2}$ blockers, and $4.03 \%$ PPIs and $\mathrm{H}_{2}$ blockers; Table 1) and 350 (56.2\%) received no AAT. The baseline demographic and clinical characteristics of patients by trial are presented in online supplementary Table 1 (for all online suppl. material, see www.karger.com/doi/10.1159/000468546). 
Table 2. Indications for antacid therapy use by trial

\begin{tabular}{lcccc}
\hline Indication & $\begin{array}{l}\text { CAPACITY } \\
\text { PIPF-004 } \\
(n=74)\end{array}$ & $\begin{array}{l}\text { CAPACITY } \\
\text { PIPF-006 } \\
(n=77)\end{array}$ & $\begin{array}{l}\text { ASCEND } \\
\text { PIPF-016 } \\
(n=122)\end{array}$ & $\begin{array}{l}\text { Pooled } \\
(n=273)\end{array}$ \\
\hline GERD & $58(78.4 \%)$ & $65(84.4 \%)$ & $100(82.0 \%)$ & $223(81.7 \%)$ \\
Dyspepsia & 0 & $5(6.5 \%)$ & $6(4.9 \%)$ & $11(4.0 \%)$ \\
Gastritis & $3(4.1 \%)$ & 0 & $5(4.1 \%)$ & $8(2.9 \%)$ \\
Prophylaxis & $2(2.7 \%)$ & $1(1.3 \%)$ & $4(3.3 \%)$ & $7(2.6 \%)$ \\
Hiatal hernia & $4(5.4 \%)$ & 0 & 0 & $6(2.2 \%)$ \\
Other & $4(5.4 \%)$ & $2(2.6 \%)$ & $1(0.8 \%)$ & $5(1.8 \%)$ \\
Nonspecific GI disease & $2(2.7 \%)$ & $2(2.6 \%)$ & $1(0.8 \%)$ & $3(1.1 \%)$ \\
Ulcer & 0 & $2(2.6 \%)$ & $1(0.8 \%)$ & $2(0.7 \%)$ \\
Barrett esophagus & $1(1.4 \%)$ & 0 & $2(1.6 \%)$ & $2(0.7 \%)$ \\
Cough & 0 & 0 & &
\end{tabular}

Values are presented as $n$ (\%). Antacid therapy consisted of proton pump inhibitors, histamine $\mathrm{H}_{2}$ receptor antagonists, or both. GERD, gastroesophageal reflux disease; GI, gastrointestinal.

Table 3. Unadjusted 1-year study outcomes by antacid therapy use

\begin{tabular}{|c|c|c|c|}
\hline & $\operatorname{AAT}^{\mathrm{a}}(n=273)$ & No $\operatorname{AAT}^{\mathrm{a}}(n=350)$ & $p$ value \\
\hline Disease progression $^{\mathrm{b}, \mathrm{c}}$ & $68(24.9 \%)$ & $107(30.6 \%)$ & 0.1187 \\
\hline All-cause mortality & $8(2.9 \%)$ & $13(3.7 \%)$ & 0.5906 \\
\hline Absolute FVC decrease $\geq 10 \%^{\mathrm{d}}$ & $14(5.1 \%)$ & $27(7.7 \%)$ & 0.1965 \\
\hline $6 \mathrm{MWD}$ decrease $\geq 50 \mathrm{~m}$ & $48(17.6 \%)$ & $72(20.6 \%)$ & 0.3479 \\
\hline \multicolumn{4}{|l|}{ Mortality } \\
\hline All-cause & $8(2.9 \%)$ & $14(4.0 \%)$ & 0.4730 \\
\hline IPF-related & $3(1.1 \%)$ & $7(2.0 \%)$ & 0.3746 \\
\hline \multicolumn{4}{|l|}{ FVC change } \\
\hline Absolute decrease $\geq 10 \%$ & $17(6.2 \%)$ & $35(10.0 \%)$ & 0.0912 \\
\hline Relative decrease $\geq 10 \%$ & $41(15.0 \%)$ & $77(22.0 \%)$ & 0.0273 \\
\hline Absolute decrease $\geq 5 \%$ & $69(25.3 \%)$ & $113(32.3 \%)$ & 0.0562 \\
\hline Relative decrease $\geq 5 \%$ & $99(36.3 \%)$ & $145(41.4 \%)$ & 0.1901 \\
\hline \multicolumn{4}{|l|}{ FVC change } \\
\hline Observed, $\%$ predicted $($ mean $\pm S D)$ & $-2.7 \pm 5.7$ & $-3.1 \pm 6.4$ & 0.4375 \\
\hline Imputed, $\%$ predicted (mean \pm SD) & $-4.6 \pm 11.3$ & $-5.9 \pm 14.5$ & 0.2091 \\
\hline Observed, L (mean \pm SD) & $-0.11 \pm 0.23$ & $-0.12 \pm 0.26$ & 0.5162 \\
\hline \multicolumn{4}{|l|}{ Other outcomes } \\
\hline $6 \mathrm{MWD}$ decrease $\geq 50 \mathrm{~m}$ & $49(17.9 \%)$ & $75(21.4 \%)$ & 0.2804 \\
\hline All-cause hospitalization & $44(16.1 \%)$ & $64(18.3 \%)$ & 0.4781 \\
\hline \multicolumn{4}{|l|}{ Side effects } \\
\hline GI side effects ${ }^{\mathrm{e}}$ & $10(3.7 \%)$ & $3(0.9 \%)$ & 0.0151 \\
\hline Infections & $184(67.4 \%)$ & $237(67.7 \%)$ & 0.9336 \\
\hline Severe pulmonary infections ${ }^{\mathrm{e}}$ & $10(3.7 \%)$ & $4(1.1 \%)$ & 0.0352 \\
\hline Duration of follow-up, days (mean $\pm \mathrm{SD}$ ) & $350.2 \pm 56.7$ & $349.7 \pm 53.3$ & 0.9181 \\
\hline
\end{tabular}

Values are presented as $n(\%)$ unless indicated otherwise. ${ }^{\text {a }}$ All patients were considered in the analyses unless noted otherwise. ${ }^{b}$ FVC decrease of $\geq 10 \%, 6 \mathrm{MWD}$ decrease of $\geq 50 \mathrm{~m}$, or death, whichever came first. ${ }^{\mathrm{c}}$ Only the first event was considered in the analysis. Events that occurred on the same day were counted in each subcategory, but contributed only a single event to the composite measure. ${ }^{\mathrm{d}}$ Includes only confirmed cases, defined as those for whom follow-up assessment was repeated $\geq 6$ weeks following initial assessment and in whom criteria for outcome were met. ${ }^{e}$ An adverse event of grade 3 or 4; grade 3 is severe and grade 4 is life-threatening. 6MWD, 6-min walking distance; AAT, antacid therapy; FVC, forced vital capacity; GI, gastrointestinal; IPF, idiopathic pulmonary fibrosis; SD, standard deviation. 
Fig. 1. Adjusted 1-year risk of progressionfree survival (a) and study outcomes (b). Progression-free survival was defined as the time to the first occurrence of a confirmed decrease of $\geq 10 \%$ in predicted forced vital capacity (FVC), a confirmed decrease of $\geq 50 \mathrm{~m}$ in the 6-min walking distance (6MWD) test, or death. The primary outcomes were an FVC decrease of $\geq 10 \%$, a $6 \mathrm{MWD}$ decrease of $\geq 50 \mathrm{~m}$, or death. Adjusted analyses included age, sex, smoking status, lung function, and comorbidity profile. AAT, antacid therapy; HR, hazard ratio; IPF, idiopathic pulmonary fibrosis.

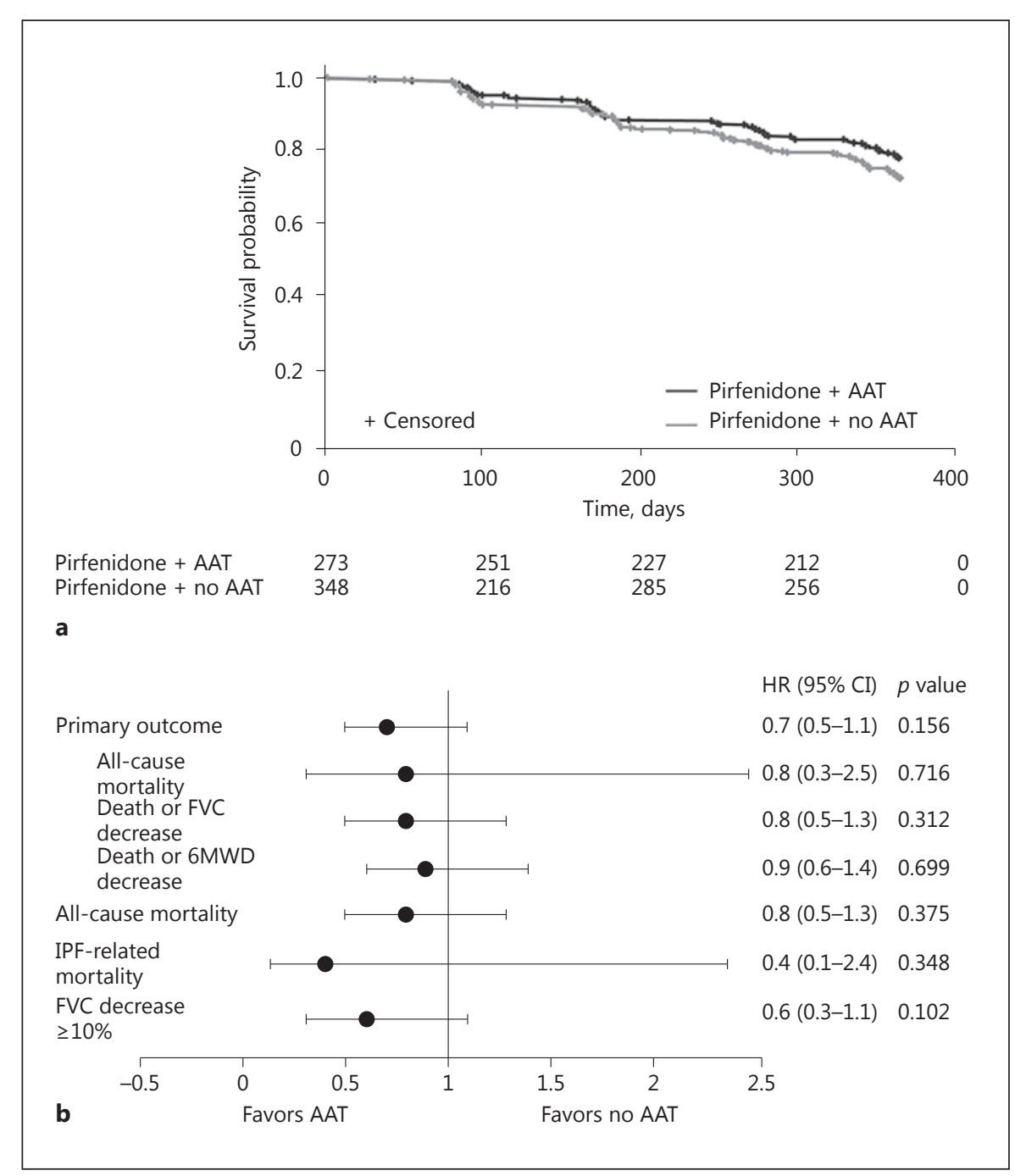

The baseline demographic and comorbidity profiles were similar between the AAT and the non-AAT group, with the exception of a significantly higher proportion of AAT users having GERD (AAT, 86.4\%; non-AAT, 24.0\%; $p<$ 0.001 ), hiatal hernia (AAT, 12.8\%; non-AAT, 5.4\%; $p=$ 0.001), Barrett esophagus (AAT, 5.1\%; non-AAT, $0.6 \%$; $p<0.001$ ), and hypercholesterolemia (AAT, 54.6\%; nonAAT, $46.0 \% ; p=0.0336$ ) (Table 1 ). The most common indications for AAT use were GERD (81.7\%), dyspepsia $(4.0 \%)$, and gastritis (2.9\%) (Table 2); most patients received omeprazole (45.8\%).

The mean follow-up time of the AAT and the nonAAT group was similar (350.2 vs. 349.7 days; $p=0.918$ ) (Table 3). The proportion of patients in the AAT and the non-AAT group was similar for each component of the disease progression composite endpoint, which included the first events of all-cause mortality (2.9 vs. $3.7 \%$; $p=$ 0.591 ), absolute decrease in FVC of $\geq 10 \%$ (5.1 vs. $7.7 \%$; $p=0.197)$, or decrease in $6 \mathrm{MWD}$ of $\geq 50 \mathrm{~m}$ (17.6 vs. $20.6 \% ; p=0.348)$. When the analyses were adjusted for confounders, disease progression was similar between AAT and non-AAT users at 1 year (hazard ratio [HR], 0.7 ; 95\% CI, 0.5-1.1; $p=0.156$ ) (online suppl. Table 2; Fig. 1). These results were similar to those from unadjusted analyses (Table 3). Also, when adjusted for confounders, the risk of all-cause or IPF-related death was not significantly reduced in the AAT group compared with the non-AAT group (all-cause mortality: HR, 0.8; 95\% CI, 0.3-2.5; $p=0.716$; IPF-related mortality: HR, 0.4 ; 95\% CI, $0.1-2.4 ; p=0.348$ ) (online suppl. Table 2; Fig. 1b). These results were similar to those from unadjusted analyses (Table 3). 
Table 4. Unadjusted 1 -year risk of study outcomes by antacid therapy use and baseline forced vital capacity ( $\%$ predicted; $<70 \%$ vs. $\geq 70 \%)$

\begin{tabular}{|c|c|c|c|c|c|c|}
\hline & \multicolumn{3}{|l|}{ FVC $<70 \%$} & \multicolumn{3}{|l|}{$\mathrm{FVC} \geq 70 \%$} \\
\hline & $\begin{array}{l}\text { AAT }^{\mathrm{a}} \\
(n=126)\end{array}$ & $\begin{array}{l}\text { no } \text { AAT }^{\text {a }} \\
(n=165)\end{array}$ & $p$ value & $\begin{array}{l}\mathrm{AAT}^{\mathrm{a}} \\
(n=147)\end{array}$ & $\begin{array}{l}\text { no } \text { AAT }^{\text {a }} \\
(n=169)\end{array}$ & $p$ value \\
\hline Disease progression $^{\mathrm{b}, \mathrm{c}}$ & $42(33.3 \%)$ & $58(35.2 \%)$ & 0.7462 & $26(17.7 \%)$ & $49(26.5 \%)$ & 0.0569 \\
\hline All-cause mortality & $7(5.6 \%)$ & $9(5.5 \%)$ & 0.9701 & $1(0.7 \%)$ & $4(2.2 \%)$ & 0.2708 \\
\hline Absolute FVC decrease $\geq 10 \%^{\mathrm{d}}$ & $6(4.8 \%)$ & $7(4.2 \%)$ & 0.8317 & $8(5.4 \%)$ & $20(10.8 \%)$ & 0.0804 \\
\hline $6 \mathrm{MWD}$ decrease $\geq 50 \mathrm{~m}$ & $31(24.6 \%)$ & $45(27.3 \%)$ & 0.6075 & $17(11.6 \%)$ & $27(14.6 \%)$ & 0.4186 \\
\hline \multicolumn{7}{|l|}{ Mortality } \\
\hline All-cause & $7(5.6 \%)$ & $9(5.5 \%)$ & 0.9701 & $1(0.7 \%)$ & $5(2.7 \%)$ & 0.1694 \\
\hline IPF-related & $3(2.4 \%)$ & $3(1.8 \%)$ & 0.7378 & $0(0.0 \%)$ & $4(2.2 \%)$ & 0.0729 \\
\hline \multicolumn{7}{|l|}{ FVC change } \\
\hline Absolute decrease $\geq 10 \%$ & $9(7.1 \%)$ & $13(7.9 \%)$ & 0.8140 & $8(5.4 \%)$ & $22(11.9 \%)$ & 0.0417 \\
\hline Relative decrease $\geq 10 \%$ & $26(20.6 \%)$ & $47(28.5 \%)$ & 0.1259 & $15(10.2 \%)$ & $30(16.2 \%)$ & 0.1119 \\
\hline Absolute decrease $\geq 5 \%$ & $34(27.0 \%)$ & $53(32.1 \%)$ & 0.3429 & $35(23.8 \%)$ & $60(32.4 \%)$ & 0.0842 \\
\hline Relative decrease $\geq 5 \%$ & $51(40.5 \%)$ & $73(44.2 \%)$ & 0.5197 & $48(32.7 \%)$ & $72(38.9 \%)$ & 0.2378 \\
\hline \multicolumn{7}{|l|}{ FVC change (mean $\pm S D)$} \\
\hline Number & 107 & 143 & & 141 & 168 & \\
\hline FVC change (observed), \% predicted & $-3.1 \pm 5.8$ & $-3.1 \pm 5.5$ & 0.9124 & $-2.4 \pm 5.7$ & $-3.2 \pm 7.1$ & 0.2843 \\
\hline FVC change (imputed), $\%$ predicted & $-6.5 \pm 13.8$ & $-6.3 \pm 13.4$ & 0.8775 & $-3.0 \pm 8.4$ & $-5.6 \pm 15.4$ & 0.0505 \\
\hline FVC change (observed), L & $-0.12 \pm 0.23$ & $-0.12 \pm 0.23$ & 0.9397 & $-0.10 \pm 0.23$ & $-0.12 \pm 0.28$ & 0.3739 \\
\hline \multicolumn{7}{|l|}{ Other outcomes } \\
\hline $6 \mathrm{MWD}$ decrease $\geq 50 \mathrm{~m}$ & $32(25.4 \%)$ & $45(27.3 \%)$ & 0.7193 & $17(11.6 \%)$ & $30(16.2 \%)$ & 0.2272 \\
\hline All-cause hospitalization & $27(21.4 \%)$ & $31(18.8 \%)$ & 0.5763 & $17(11.6 \%)$ & $29(15.7 \%)$ & 0.2815 \\
\hline \multicolumn{7}{|l|}{ Side effects } \\
\hline GI side effects ${ }^{\mathrm{e}}$ & $5(4.0 \%)$ & $1(0.6 \%)$ & 0.0455 & $5(3.4 \%)$ & $2(1.1 \%)$ & 0.1438 \\
\hline Infections & $90(71.4 \%)$ & $122(73.9 \%)$ & 0.6332 & $94(63.9 \%)$ & $115(62.2 \%)$ & 0.7382 \\
\hline Severe pulmonary infections $\mathrm{s}^{\mathrm{e}}$ & $8(6.3 \%)$ & $3(1.8 \%)$ & 0.0446 & $2(1.4 \%)$ & $1(0.5 \%)$ & 0.4329 \\
\hline Duration of follow-up, days (mean \pm SD) & $338.3 \pm 77.0$ & $341.4 \pm 68.2$ & 0.7198 & $360.3 \pm 26.3$ & $357.2 \pm 33.3$ & 0.3387 \\
\hline
\end{tabular}

Values are presented as $n$ (\%) unless indicated otherwise. ${ }^{a}$ All patients were considered in the analyses unless noted otherwise. ${ }^{b} \mathrm{FVC}$ decrease of $\geq 10 \%, 6 \mathrm{MWD}$ decrease of $\geq 50 \mathrm{~m}$, or death, whichever came first. ${ }^{\mathrm{c}}$ Only the first event was considered in the analyses. ${ }^{\mathrm{d}}$ Includes only confirmed cases, defined as those for whom follow-up assessment was repeated $\geq 6$ weeks following initial assessment and in whom criteria for outcome were met. ${ }^{\mathrm{e}}$ An adverse event of grade 3 or 4; grade 3 is severe and grade 4 is life-threatening. $6 \mathrm{MWD}$, 6-min walking distance; AAT, antacid therapy; FVC, forced vital capacity; GI, gastrointestinal; IPF, idiopathic pulmonary fibrosis; SD, standard deviation.

AAT users had similar mean changes in FVC from baseline to week 52 compared with non-AAT users (Table 3). With the exception of a relative FVC decline of $\geq 10 \%$, absolute and relative declines in FVC, a decrease in $6 \mathrm{MWD}$ of $\geq 50 \mathrm{~m}$, and hospitalization rates after 52 weeks were similar between the AAT and the non-AAT patient group. The results were largely unchanged when patients who received only PPIs and not $\mathrm{H}_{2}$ blockers were considered (data not shown).

The pirfenidone dose intensity of $90 \%$ was not significantly different between the AAT and the non-AAT group (68.9 vs. $67.4 \% ; p=0.730$ ).

When patients were stratified by mean baseline FVC ( $\geq 70 \%$ or $<70 \%$ ), no significant differences were observed in either stratified group in disease progression or mor- tality between the AAT and the non-AAT group (Table 4). The unadjusted disease progression rates of patients with a percent predicted FVC of $<70 \%$ (AAT, 42 [33.3\%]; non-AAT, 58 [35.2\%]; $p=0.746)$ and of patients with a percent predicted FVC of $\geq 70 \%$ (AAT, 26 [17.1\%]; non-AAT, 49 [26.5\%]; $p=0.057$ ) were similar. Furthermore, no significant differences were observed in 6MWD decrease of $\geq 50 \mathrm{~m}$ and all-cause hospitalization rate between the AAT and the non-AAT groups when stratified by percent predicted FVC.

Patients who received AAT had significantly more severe GI-related AEs than those who did not (3.7 vs. $0.9 \%$; $p=0.015$ ) (Table 3). Overall, the incidence of infections was similar between the AAT and the non-AAT group (67.4 vs. $67.7 \% ; p=0.934)$. More severe pulmonary infec- 
tions were observed in the AAT group than in the nonAAT group (3.7 vs. $1.1 \% ; p=0.035$ ). Patients with a percent predicted FVC of $<70 \%$ who received AAT had significantly more GI-related AEs and severe pulmonary infections than those who did not receive AAT.

\section{Discussion}

In this post hoc analysis, both AAT and non-AAT users at baseline had similar clinical outcomes at 52 weeks. No association between AAT use and disease progression or mortality was observed in patients who received AAT in combination with pirfenidone.

The 2015 treatment guidelines for IPF make a conditional recommendation for the use of AAT based on results from retrospective studies suggesting that patients with IPF who received AAT had slower disease progression and improved survival compared with patients who did not receive AAT $[28,29]$. In a prespecified post hoc analysis of 3 IPFnet-sponsored trials, data were collected prospectively at baseline and longitudinally during follow-up. In those IPFnet-sponsored studies, patients with IPF who received AAT for various indications, but not as a designated treatment for IPF, had significantly less deterioration of pulmonary function than those not receiving AAT; however, no between-group differences in allcause mortality or all-cause hospital admission rates were observed $[29,30]$. Other reports suggested that AAT may help stabilize IPF and result in fewer acute exacerbations [31]. The results of our post hoc analysis do not support a clinically meaningful beneficial effect of AAT in patients with IPF receiving pirfenidone. This observation is in agreement with a previously published post hoc analysis comparing AAT use and non-AAT use in patients randomized to placebo in the same clinical trials [21]. Indeed, we observed no clear benefit of AAT use for the composite outcome of PFS or all-cause and IPF-related mortality rates.

Possible causes for discrepancies between this and previous studies may relate to differences in the patient population. Although differences between trials cannot be excluded, the clustering model adjusted for between-group differences. The CAPACITY and ASCEND studies excluded patients awaiting lung transplantation. In comparison with the IPFnet-sponsored trials, with the exception of PANTHER, the pooled CAPACITY and ASCEND studies showed higher mean baseline percentages of predicted FVC $(\approx 70 \%)$ compared with $\approx 59 \%$ in the STEPIPF study, $\approx 58.5 \%$ in the ACE-IPF study, and $\approx 71 \%$ in

Antacid Therapy and Pirfenidone Use in Idiopathic Pulmonary Fibrosis the PANTHER study $[3,4,6,29]$. AAT may also benefit patients awaiting lung transplantation [32]. As such, it is possible that those who had more severe GERD and/or higher GERD activity responded more effectively to AAT. In this study, 70\% FVC stratification was performed to understand if more advanced disease had different outcomes. Patients with an FVC of $<70 \%$ who received AAT had PFS and mortality rates similar to those who did not receive AAT.

A potential benefit of AAT in patients receiving pirfenidone cannot be ruled out completely. The estimated HRs suggest a trend favoring AAT, as does the observation that a lower proportion of AAT users experienced a relative, but not absolute, FVC decline of $\geq 10 \%$. This may represent a false-positive finding, owing to the limitations inherent in post hoc analyses. Our analysis may not have been adequately powered to detect further significant differences. Moreover, it cannot be excluded that drug interactions between PPI and pirfenidone may have altered outcomes in either way. Another possibility is that a between-group imbalance in dose intensity due to different AEs may have influenced the results; however, in our analyses, there was no significant difference in pirfenidone dose intensities between the AAT and the non-AAT group. These inconsistencies underscore the need for prospective randomized, double-blind, placebo-controlled studies assessing the role of AAT in IPF.

AAT may also be associated with more frequent and severe AEs. An association between AAT use and more frequent GI side effects was observed. Moreover, severe pulmonary infections occurred at a significantly higher rate in patients who received AAT. Previous studies have reported similar results, with AAT use resulting in increased rates of ventilator-associated and community-acquired pneumonia compared with non-AAT use $[33,34]$. This is further supported by a recent systematic review in which the most frequently reported $\mathrm{AE}$ was communityacquired pulmonary infection [35].

This study had limitations. This was a post hoc analysis and therefore the findings are to be interpreted with caution. The study population was not randomized for AAT or stratified for imbalances in comorbidities. Patients at baseline who received AAT may have had more GI comorbidities, which is potentially a confounding issue. Although the analyses were adjusted - based on observed factors - to address potential confounders, the results may be biased due to differences in unobserved factors. The population was grouped by baseline exposure to AAT. The analysis did not account for AAT use that oc-

Respiration 2017;93:415-423 421 
curred after baseline in the non-AAT group, nor the duration of AAT exposure prior to baseline. Time-dependent covariate analysis was not possible given the limitations of the data. Because of the relatively small sample size, these analyses were probably underpowered to detect meaningful differences; however, a formal power analysis was not performed. Patients with advanced disease, such as those awaiting lung transplantation or those with an FVC of $<50 \%$, were not included in the trials. Finally, a longer trial time of $>52$ weeks, and consequently a longer duration of AAT, may have a positive effect on disease progression.

\section{Conclusions}

This study does not suggest that AAT might be beneficial as a treatment for IPF in combination with pirfenidone. The data suggest that patients with IPF receiving pirfenidone treatment who are receiving AAT might be at a higher risk of severe pulmonary infection than those not receiving AAT, and may have more GI side effects. Therefore, we believe that the role of AAT in IPF, either alone or in combination with antifibrotic drugs, should be prospectively assessed in a randomized, double-blind, placebo-controlled trial before being considered a specific treatment for IPF. Until these trials are completed, neither the effectiveness nor the safety of AAT as a treatment of IPF can be supposed.

\section{Acknowledgments}

Support for third-party writing assistance for the manuscript, furnished by Denise Kenski, PhD, and William Turner, $\mathrm{PhD}$, of Health Interactions Inc., was provided by F. Hoffmann-La Roche Ltd. This study was funded by F. Hoffmann-La Roche Ltd./Genentech, Inc.

\section{Financial Disclosure and Conflicts of Interest}

Dr. Kreuter received research grants and personal fees from Boehringer Ingelheim and InterMune/Roche. Dr. Spagnolo received personal fees from Boehringer Ingelheim, Chiesi Farmaceutici, Genentech, InterMune/Roche, and Santhera Pharmaceuticals. Dr. Wuyts received research grants from InterMune/Roche and personal fees from Bayer, Boehringer Ingelheim, and Roche. Dr. Renzoni received personal fees from Boehringer Ingelheim, InterMune/Roche, and Takada. Dr. Koschel received personal fees from Boehringer Ingelheim and InterMune/Roche. Dr. Bonella received research grants and nonfinancial support from Boehringer Ingelheim, Roche, and Serendex. Dr. Maher participated in research with Gilead and received research grants from GlaxoSmithKline, Novartis, and UCB and personal fees from Apellis, Bayer, Biogen Idec, Boehringer Ingelheim, DOSA, GlaxoSmithKline, Prometic, Roche, Sanofi, and UCB. Dr. Kolb received research grants from Actelion, Boehringer Ingelheim, InterMune/Roche Canada, and Respivert and personal fees from AstraZeneca, Boehringer Ingelheim, Genoa, Gilead, GlaxoSmithKline, Prometic, and Roche. Dr. Weycker is an employee of Policy Analysis Inc. Dr. Kirchgässler is an employee of Roche. Dr. Costabel received research grants and nonfinancial support from Boehringer Ingelheim and InterMune/ Roche and personal fees from Bayer, Boehringer Ingelheim, Centocor, Gilead, GlaxoSmithKline, and InterMune/Roche.

\section{References}

1 Raghu G, Collard HR, Egan JJ, Martinez FJ, Behr J, Brown KK, Colby TV, Cordier JF, Flaherty KR, Lasky JA, Lynch DA, Ryu JH, Swigris JJ, Wells AU, Ancochea J, Bouros D, Carvalho C, Costabel U, Ebina M, Hansell DM, Johkoh T, Kim DS, King TE Jr, Kondoh Y, Myers J, Muller NL, Nicholson AG, Richeldi L, Selman M, Dudden RF, Griss BS, Protzko SL, Schunemann HJ; ATS/ERS/JRS/ALAT Committee on Idiopathic Pulmonary Fibrosis: An official ATS/ERS/JRS/ALAT statement: idiopathic pulmonary fibrosis: evidence-based guidelines for diagnosis and management. Am J Respir Crit Care Med 2011;183:788-824.

2 Richeldi L, du Bois RM, Raghu G, Azuma A, Brown KK, Costabel U, Cottin V, Flaherty KR, Hansell DM, Inoue Y, Kim DS, Kolb M, Nicholson AG, Noble PW, Selman M, Taniguchi H, Brun M, Le Maulf F, Girard M, Stowasser S, Schlenker-Herceg R, Disse B, Collard HR; INPULSIS Trial Investigators: Effi- cacy and safety of nintedanib in idiopathic pulmonary fibrosis. N Engl J Med 2014;370: 2071-2082.

3 King TE Jr, Bradford WZ, Castro-Bernardini S, Fagan EA, Glaspole I, Glassberg MK, Gorina E, Hopkins PM, Kardatzke D, Lancaster L, Lederer DJ, Nathan SD, Pereira CA, Sahn SA, Sussman R, Swigris JJ, Noble PW; ASCEND Study Group: A phase 3 trial of pirfenidone in patients with idiopathic pulmonary fibrosis. N Engl J Med 2014;370:20832092.

4 Noble PW, Albera C, Bradford WZ, Costabel U, Glassberg MK, Kardatzke D, King TE Jr, Lancaster L, Sahn SA, Szwarcberg J, Valeyre D, du Bois RM; CAPACITY Study Group: Pirfenidone in patients with idiopathic pulmonary fibrosis (CAPACITY): two randomised trials. Lancet 2011;377:1760-1769.

5 Taniguchi H, Ebina M, Kondoh Y, Ogura T, Azuma A, Suga M, Taguchi Y, Takahashi H, Nakata K, Sato A, Takeuchi M, Raghu G, Ku- doh S, Nukiwa T; Pirfenidone Clinical Study Group in Japan: Pirfenidone in idiopathic pulmonary fibrosis. Eur Respir J 2010;35: 821-829.

6 Noble PW, Albera C, Bradford WZ, Costabel U, du Bois RM, Fagan EA, Fishman RS, Glaspole I, Glassberg MK, Lancaster L, Lederer DJ, Leff JA, Nathan SD, Pereira CA, Swigris JJ, Valeyre D, King TE Jr: Pirfenidone for idiopathic pulmonary fibrosis: analysis of pooled data from three multinational phase 3 trials. Eur Respir J 2016;47:243-253.

7 Kreuter M, Ehlers-Tenenbaum S, Palmowski K, Bruhwyler J, Oltmanns U, Muley T, Heussel CP, Warth A, Kolb M, Herth FJ: Impact of comorbidities on mortality in patients with idiopathic pulmonary fibrosis. PLoS One 2016;11:e0151425.

8 Katz PO, Gerson LB, Vela MF: Guidelines for the diagnosis and management of gastroesophageal reflux disease. Am J Gastroenterol 2013;108:308-328. 
9 Gribbin J, Hubbard R, Smith C: Role of diabetes mellitus and gastro-oesophageal reflux in the aetiology of idiopathic pulmonary fibrosis. Respir Med 2009;103:927-931.

10 Patti MG, Tedesco P, Golden J, Hays S, Hoopes C, Meneghetti A, Damani T, Way LW: Idiopathic pulmonary fibrosis: how often is it really idiopathic? J Gastrointest Surg 2005;9:1053-1056; discussion 1056-1058.

11 Raghu G, Freudenberger TD, Yang S, Curtis JR, Spada C, Hayes J, Sillery JK, Pope CE 2nd, Pellegrini CA: High prevalence of abnormal acid gastro-oesophageal reflux in idiopathic pulmonary fibrosis. Eur Respir J 2006;27: 136-142.

12 Tobin RW, Pope CE 2nd, Pellegrini CA, Emond MJ, Sillery J, Raghu G: Increased prevalence of gastroesophageal reflux in patients with idiopathic pulmonary fibrosis. Am J Respir Crit Care Med 1998;158:1804-1808.

13 Ley B, Collard HR: Epidemiology of idiopathic pulmonary fibrosis. Clin Epidemiol 2013;5: 483-492.

14 Sonnenberg A: Effects of environment and lifestyle on gastroesophageal reflux disease. Dig Dis 2011;29:229-234.

15 Gnanapandithan K, Popkin JH, Devadoss R, Martin K: Gastroesophageal reflux and idiopathic pulmonary fibrosis: a long term relationship. Respir Med Case Rep 2016;17:4043.

16 Hershcovici T, Jha LK, Johnson T, Gerson L, Stave C, Malo J, Knox KS, Quan S, Fass R: Systematic review: the relationship between interstitial lung diseases and gastro-oesophageal reflux disease. Aliment Pharmacol Ther 2011;34:1295-1305.

17 Wuyts WA, Collard HR: Gastroesophageal reflux in idiopathic pulmonary fibrosis: more than a gut feeling? Respiration 2016;91:1-2.

18 Kreuter M, Kirsten D, Bahmer T, Penzel R, Claussen M, Ehlers-Tenenbaum S, Muley T, Palmowski K, Eichinger M, Leider M, Herth FJ, Rabe KF, Bittmann I, Warth A: Screening for Helicobacter pylori in idiopathic pulmonary fibrosis lung biopsies. Respiration 2016; 91:3-8.
19 Ghebre Y, Raghu G: Proton pump inhibitors in IPF: beyond mere suppression of gastric acidity. QJM 2016;109:577-579.

20 Raghu G, Rochwerg B, Zhang Y, Garcia CA, Azuma A, Behr J, Brozek JL, Collard HR, Cunningham W, Homma S, Johkoh T, Martinez FJ, Myers J, Protzko SL, Richeldi L, Rind D, Selman M, Theodore A, Wells AU, Hoogsteden H, Schunemann HJ; American Thoracic Society, European Respiratory Society, Japanese Respiratory Society, and Latin American Thoracic Association: An official ATS/ERS/ JRS/ALAT Clinical Practice Guideline: treatment of idiopathic pulmonary fibrosis. An update of the 2011 Clinical Practice Guideline. Am J Respir Crit Care Med 2015;192:e3-e19.

21 Kreuter M, Wuyts W, Renzoni E, Koschel D, Maher TM, Kolb M, Weycker D, Spagnolo P, Kirchgaessler KU, Herth FJ, Costabel U: Antacid therapy and disease outcomes in idiopathic pulmonary fibrosis: a pooled analysis. Lancet Respir Med 2016;4:381-389.

22 Raghu G, Crestani B, Bailes Z, Schlenker-Herceg R, Costabel U: Effect of anti-acid medication on reduction in FVC decline with nintedanib.Eur RespirJ2015;46(suppl59):OA4502.

23 Wuyts WA, Bonella F, Costabel U, Cottin V, Kreuter M, Poletti V, Spagnolo P: An important step forward, but still a way to go. Am J Respir Crit Care Med 2016;193:340-341.

24 Raghu G: Anti-acid treatment in patients with IPF: interpret results from post-hoc, subgroup, and exploratory analyses with great caution. Lancet Respir Med 2016;4:e46-e47.

25 Kreuter M, Wuyts W, Renzoni E, Koschel D, Maher T, Kolb M, Weycker D, Spagnolo P, Kirchgaessler K, Herth F, Costabel U: Antiacid treatment in patients with IPF: interpret results from post-hoc, subgroup, and exploratory analyses with great caution - authors' reply. Lancet Respir Med 2016;4:e48.

26 Allison PD: Survival Analysis Using SAS: A Practical Guide, ed 2. Cary, NC, SAS Institute, 2010.

27 Pencina MJ, D'Agostino RB Sr, D'Agostino RB Jr, Vasan RS: Evaluating the added predictive ability of a new marker: from area under the ROC curve to reclassification and beyond. Stat Med 2008;27:157-172; discussion 207-212.
28 Raghu G, Meyer KC: Silent gastro-oesophageal reflux and microaspiration in IPF: mounting evidence for anti-reflux therapy? Eur Respir J 2012;39:242-245.

29 Lee JS, Collard HR, Anstrom KJ, Martinez FJ, Noth I, Roberts RS, Yow E, Raghu G; IPFnet Investigators: Anti-acid treatment and disease progression in idiopathic pulmonary fibrosis: an analysis of data from three randomised controlled trials. Lancet Respir Med 2013;1:369-376.

30 Lee JS, Ryu JH, Elicker BM, Lydell CP, Jones KD, Wolters PJ, King TE Jr, Collard HR: Gastroesophageal reflux therapy is associated with longer survival in patients with idiopathic pulmonary fibrosis. Am J Respir Crit Care Med 2011;184:1390-1394.

31 Raghu G, Yang ST, Spada C, Hayes J, Pellegrini CA: Sole treatment of acid gastroesophageal reflux in idiopathic pulmonary fibrosis: a case series. Chest 2006;129:794-800.

32 Linden PA, Gilbert RJ, Yeap BY, Boyle K, Deykin A, Jaklitsch MT, Sugarbaker DJ, Bueno R: Laparoscopic fundoplication in patients with end-stage lung disease awaiting transplantation. J Thorac Cardiovasc Surg 2006; 131:438-446.

33 Myles PR, Hubbard RB, Gibson JE, Pogson Z, Smith CJ, McKeever TM: The impact of statins, ACE inhibitors and gastric acid suppressants on pneumonia mortality in a UK general practice population cohort. Pharmacoepidemiol Drug Saf 2009;18:697-703.

34 Ibrahim EH, Tracy L, Hill C, Fraser VJ, Kollef $\mathrm{MH}$ : The occurrence of ventilator-associated pneumonia in a community hospital: risk factors and clinical outcomes. Chest 2001;120: 555-561.

35 Abramowitz J, Thakkar P, Isa A, Truong A, Park C, Rosenfeld RM: Adverse event reporting for proton pump inhibitor therapy: an overview of systematic reviews. Otolaryngol Head Neck Surg 2016;155:547-554.
Antacid Therapy and Pirfenidone Use in Idiopathic Pulmonary Fibrosis
Respiration 2017;93:415-423 DOI: $10.1159 / 000468546$ 